University of Nebraska - Lincoln

DigitalCommons@University of Nebraska - Lincoln

To Improve the Academy

Professional and Organizational Development

Network in Higher Education

1995

\title{
A Special Colloquium on Teaching Excellence to Foster Collegiality and Enhance Teaching at a Research University
}

James K. Wangberg

Jane V. Nelson

Thomas G. Dunn

Follow this and additional works at: https://digitalcommons.unl.edu/podimproveacad

Part of the Higher Education Administration Commons

Wangberg, James K.; Nelson, Jane V.; and Dunn, Thomas G., "A Special Colloquium on Teaching Excellence to Foster Collegiality and Enhance Teaching at a Research University" (1995). To Improve the Academy. 349.

https://digitalcommons.unl.edu/podimproveacad/349

This Article is brought to you for free and open access by the Professional and Organizational Development Network in Higher Education at DigitalCommons@University of Nebraska - Lincoln. It has been accepted for inclusion in To Improve the Academy by an authorized administrator of DigitalCommons@University of Nebraska - Lincoln. 


\section{A Special Colloquium on Teaching Excellence to Foster Collegiality and Enhance Teaching at a Research University}

\section{James K. Wangberg}

University of Wyoming

\section{Jane V. Nelson}

University of Wyoming

\section{Thomas G. Dunn}

University of Wyoming

This article describes an annual three-day colloquium on teaching sponsored by the Center for Teaching Excellence (CTE) at the University of Wyoming. Deans and directors nominate participants for the colloquium. Plenary and concurrent sessions are led by a mix of external and internal speakers and panelists. Participants find the greatest benefit to be the collegiality fostered by the event. Consistent support from the president, provost, and deans makes the colloquium highly visible and helps to enhance teaching throughout the university.

Although the task of reinforcing the institutional teaching mission and strengthening collegiality among faculty members is common to many campuses, it presents a special challenge to research universi- 
ties. Whatever their missions, campuses often need to develop, maintain, or enhance the commitment to teaching.

Wyoming has the distinction of being the only state with a single four-year baccalaureate degree granting institution: the University of Wyoming. As a Carnegie II research university, UW's mission strongly emphasizes research, extension, and service. However, its long-standing principal priority is a firm commitment to excellence in undergraduate education.

This article summarizes how the special Colloquium on Teaching Excellence was developed at the University of Wyoming to foster collegiality and enhance its teaching mission. A colloquium of this type could be replicated at other colleges and universities to meet similar needs.

\section{Colloquium History and Philosophy}

The concept for a teaching colloquium at the University of Wyoming arose from a one-day training session on teaching developed for graduate assistants by an ad hoc group of faculty. Its success resulted in an expanded five-day session offered to the faculty at large in May, 1986. This teaching colloquium was very well-received by the participants, but financial constraints precluded its continuation. In 1990 the idea was revived with the creation of the Center for Teaching Excellence (CTE). One of the first of CTE's ventures was the Colloquium on Teaching Excellence, now in its fifth year.

The CTE's colloquium has aimed to reinforce the university's teaching commitment, to provide greater faculty development opportunities in teaching, and to recognize excellent and dedicated teaching faculty. The colloquium bears a dual charge: to offer an outstanding professional development opportunity for all members of the teaching community (Weimer, 1991) and to provide an annual event that confers a level of prestige on the participants. Hence, outstanding teachers may be selected as participants in order to recognize their achievements and to reward them with a meaningful professional development activity. Individuals having some difficulties in teaching, but with the desire and dedication to make improvements, may also be involved. The colloquium is specially designed to increase 
collegiality among teachers in all disciplines and strengthen the overall academic community.

\section{Colloquium Structure and Format}

The three-day colloquium takes place on the University of Wyoming campus in Laramie during the third week of May each year, two weeks after the university commencement but prior to the first summer session. Apart from a few intersession courses, no classes are being taught at the time. Most faculty, including those with nine-month appointments, remain on campus for the May interim between spring semester and summer activities.

To ensure small and highly interactive sessions, participation in the colloquium is limited to $65-75$ faculty (approximately $10 \%$ of the total faculty), nominated by their academic deans and directors. The number of participants from each college or school is proportional to the size of their academic units. The deans and directors use their own criteria for selection, and their nominations produce a satisfactory mix: junior and senior faculty members, people recognized for outstanding teaching, and those who are experiencing some difficulties with teaching. All nominees express an interest in teaching improvement. A few "at large" nominations permit some flexibility in accommodating special circumstances.

The colloquium program is designed for intensive and interactive learning. (See Appendix A for a sample program.) Each of the threeday sessions begins at 8:00 am and concludes by 5:00 pm. Program sessions are punctuated by morning and afternoon breaks, where refreshments are provided, and by lunch, which is also provided. Department chairs, deans, directors, vice presidents, trustees, key donors, legislators, and the University president are invited to attend a special reception at the end of the colloquium's first day, with colloquium participants and their spouses or friends. A typical colloquium is scheduled for Monday, Tuesday, and Thursday. First year participants recommended that we schedule the Wednesday break as a respite from such an intensive program. The unscheduled day provides time for informal gatherings, follow-up on inspirational ideas, and some introspection before embarking on new topics and 
new speakers on the final day. Time for informal contacts is an important element in such conferences (Sorcinelli \& Price, 1990).

The colloquium sessions are led by a variety of internal and external speakers, panelists, workshop leaders, and facilitators. Each year, one or two external speakers of national stature and reputation are invited as keynote speakers and facilitators for follow-up workshops. The external speakers receive stipends. UW faculty and other members of the university's academic community lead the majority of colloquium sessions. They are invited by the CTE to participate, usually without remuneration; and they contribute because of a sincere interest in serving the university and interacting with colleagues. In some years the budget has permitted a $\$ 100$ honorarium for internal speakers.

On the opening morning of the colloquium, after welcomes and introductions, an external speaker introduces the keynote theme in a plenary session. In the afternoon, this speaker leads some workshop sessions to establish the interactive nature of the colloquium. For the second and third days, the daily format usually incudes an opening session for the entire group and one or two common group sessions at other times in the day. The majority of the day is arranged around a menu of concurrent sessions. Most of these sessions are repeated once, but because of the diversity of offerings, participants cannot attend every session. Dividing the whole group into smaller sessions of 8-20 participants promotes active discussion in a workshop-like setting.

The colloquium theme differs each year, and there are always new seminar titles and workshop activities. Some topics are repeated or expanded from previous colloquia due to continued relevance and popularity. As advocated by Sorcinelli and Price (1990), the offerings attempt to cover a range of learning experiences. Popular themes include the following:

cooperative and active learning assessing learning

effective use of discussion

distance learning

involving students in teaching classroom research and assessment teaching large classes diversity teaching and the Internet multimedia and instruction exemplary classrooms teaching freshmen 
technology in the classroom application of Myers-Briggs personality indicators student and faculty expectations in the classroom writing and math across the curriculum legal issues teaching problem solving and critical thinking teaching styles

The cost of the colloquium has ranged from $\$ 5000-10,000$ per year, depending on the number of external speakers and their fees. Costs are covered by the CTE operating budget (state appropriations) and from extramural grants. Participants pay no registration costs or fees and there are no costs to the colleges or academic units they represent. The CTE provides all participants with a program notebook, speakers' materials, and one or two books related to college teaching or learning, such as Sheila Tobias's They're Not Dumb, They're Different (1990), 147 Practical Tips for Teaching Professors (1990), and Quick Hits: Successful Strategies by Award Winning Teachers (1994). Door prizes are awarded to participants throughout the colloquium. At the end of the colloquium participants receive a certificate documenting their participation.

\section{Fostering Collegiality}

Through formal evaluations and informal comments the participants consistently applaud the colloquium and reveal the many ways it benefits them professionally. While recognizing the valure of the speakers and topics, they find the most beneficial aspect of the colloquium to be the way in which it fosters collegiality. Many confess that they rarely get to know people outside of their own departments, not to mention their schools or colleges, therefore they find the opportunity to interact with faculty from all disciplines to be highly stimulating and rewarding, an outcome that is consistent with others' findings (Lamber et al., 1993). They discover affinities in their teaching that they did not anticipate or consider as possibilities, and they make commitments to stay in contact. This capacity of the colloquium to foster collegiality is the principal reason why colloquia programs 
now have longer interactive sessions and more lengthy breaks. Faculty value most the time they can talk with each other.

By design, the colloquium creates multiple opportunities to foster collegiality. Limited registration and orchestrated attendance in concurrent sessions helps achieve this objective. Facilitators, speakers, and panel moderators who understand active learning and discussion strategies further promote a collegial environment. Other strategies encourage people to mix and to enjoy each other's company. For example, participants arrive on time to sessions for the pleasure and humor of watching each other win door prizes. At lunch the first day, participants are surprised by prearranged place settings that seat them with faculty from other departments and colleges. After this first assigned seating, it is no longer necessary to prevent self segregation by discipline; the participants continue discussions with their new colleagues or actively make more acquaintances. Even after the colloquium has ended, the CTE continues to promote collegiality by including colloquium participants on an e-mail list and providing them with special and advanced notifications and invitations to other teaching events. Past colloquium attendees may be asked to participate in future colloquia as seminar speakers or facilitators, so many of the contacts that are made through the colloquia continue to be cultivated.

\section{Evaluation of Participants' Experiences}

Every colloquium and all speakers and topics are formally evaluated by participants and colloquium organizers, and such evaluations are often useful in generating or improving follow-up activities (Sorcinelli \& Price, 1990). Participants are asked to rate, on a 1-5 scale, both the effectiveness and the usefulness of the plenary sessions and the concurrent presentations/workshops. They also evaluate the colloquium in general on such issues as its length, the time of year that it is offered, the mix of speakers, and the material presented (see Appendix B for a sample evaluation form). The ratings reflect overall satisfaction with the colloquium, which participants express in testimonials such as the following: 
"I have learned to be more creative."

"I have benefitted personally by knowing that there are many at the University of Wyoming who know we can and need to do better teaching."

"I felt renewed enthusiasm for my teaching."

"It was very informative to hear and experience different teaching techniques."

“. . provided a rare opportunity to exchange ideas with colleagues across the university."

“.. . inspired me. .."

"... made me realize that there was a supportive community of faculty who were interested in improving teaching at the university."

“... energizing. .."

"I was able to interact with faculty from the university as well as the community colleges."

“. . . improved my teaching. .."

"I have learned a lot of teaching skills."

"Also helpful was the opportunity to meet with successful teachers about their tactics and methods."

"Attending the CTE colloquium . . . last spring made me realize that my own colleagues have much to teach me about good teaching. ..."

This intensive teaching colloquium has proved its benefits on our campus. For three full days, ten percent of the university's faculty engage in intense conversations about teaching. Afterwards, many confess that they haven't devoted that much time or thought, either independently or with others, to the broad aspects of teaching during an entire year. They are rejuvenated and stimulated.

\section{Enhancing Recognition of Teaching}

Considerable planning goes into the colloquium to ensure its overall quality and to create the perception that it is a premier university event. The colloquium aims to highlight the importance of under- 
graduate education. The close involvement of academic deans, directors, and the provost gives the colloquium credibility and underscores institutional commitment.

Dean and director involvement began with their unanimous endorsement of the colloquium concept and has been sustained by their annual selection of faculty participants. They cooperate by forwarding nominations to the CTE to fill their college or school allotments, and many seek additional at-large nominations. Initially, some deans rewarded their faculty with small stipends for their participation, but the deans have discovered that their recognition and endorsement of the event and the benefits to the participants are adequate rewards.

Commitment to the colloquium by the president and the provost has also reinforced the institution's recognition of teaching. Each year the provost and/or the president have been colloquium speakers. The president and provost always attend some of the sessions and join participants at the reception or during the luncheons. Their visibility underscores the university's commitment to teaching. Attendance at the reception and at occasional sessions by deans and directors strengthens this message, as do reception invitations to trustees, significant university donors, and the department heads. Media releases about the colloquium in university publications and newspapers, and radio interviews also enhance this message.

Quality meals, excellent program materials, free books, certificates awarded at the conclusion, and a thoroughly professional atmosphere further promote the colloquium as a premier event in recognition of teaching faculty. In fact, it is a rare professional development opportunity for faculty since it is provided at no cost to the registrants. Evidence of the colloquium's success is also contributed to a greater desire on the part of faculty to be participants in the event. After four colloquia, many faculty members ask how they can be involved and, in some cases, colleges have created waiting lists of individuals looking forward to their invitations.

\section{Opportunities for Change and Growth}

Because of its success, the CTE will continue to sponsor this annual colloquium, but at the same time, we expect that the colloquium 
will not only evolve but also help to generate other opportunities for professional development in teaching. One recent change in the colloquium has been greater outreach to faculty members from other state institutions. Last year, for the first time, the CTE invited each president of Wyoming's five community colleges to send a faculty member to the colloquium. Many responded to the invitation and all of them appreciated the opportunity to connect with the university in a teaching conference. The objectives were to recognize and involve the entire higher education community in the state and to broaden dialogue among colleagues at the university and the community colleges. To expand this dialogue, the 1995 colloquium included community college faculty as program organizers and as panelists. Involving community college faculty has increased communication and also created significant goodwill between the institutions.

In addition, the colloquium's visibility is helping to create comparable events in colleges, schools, and departments. Several participants have expressed interest in using colloquium themes in teaching workshops in their units or developing teaching workshops based on colloquium topics. Faculty members have also asked the CTE to remove the ceiling on colloquium attendance. Because increasing attendance would alter the workshop setting, colloquium organizers are considering other options, such as sponsoring another multi-day event in the month-long interim between fall and spring semesters.

The colloquium's success has also generated greater opportunities for donor support and extramural funding. Extramural funding for the colloquium itself has increased, and the CTE has also gained larger grants for other programs because of the colloquium. The companies providing support for these activities (US WEST and the Chicago and NorthWestern Transportation Company) are prominently recognized in all published materials and news releases, and they are acknowledged in correspondence and annual reports. Sponsorship by one corporation can be a catalyst for sponsorship by others who invest in education or want their name associated with teaching excellence. 


\section{Opportunities for Others}

This colloquium has worked well in our institution, campus culture, and state setting, but other campuses may wish to modify the design to make it relevant for them. Not every university has an adequate budget or support for such an undertaking. The cost of the colloquium could be significantly reduced while preserving the important elements of the program in a variety of ways. Using local faculty members instead of external speakers would yield major savings, and recognizing excellent faculty within one's own institution may well compensate for the lack of a nationally-known outside speaker (Sorcinelli \& Price, 1990; Weimer, 1991). The length of the colloquium might be reduced or even limited to a single day. Savings could also be gained through less expensive meals and more modest accommodations for receptions. One could also seek greater extramural funding and more external sponsors for the colloquium. An expensive colloquium price tag is not a prerequisite for success in fostering collegiality and enhancing teaching, so these and other strategies (see Whitcomb, 1986) may help overcome low budgets.

\section{Conclusion}

The University of Wyoming CTE sponsors many teaching events throughout the year, including brown-bag seminars, a year-long series of colloquia for new faculty, a small grants program for travel and curriculum innovation, the development of exemplary classrooms, and assistance to individual teachers. Among these projects, the annual three-day colloquium is the premier event. Planning for such a major undertaking starts well over a year in advance, and the weeks directly preceding the event can seem impossibly full, but the results always justify the effort. Almost all faculty who attend gain new colleagues and a renewed or heightened interest in teaching. Many participants continue to attend CTE activities through the year, and some have made significant changes in their teaching styles. All evidence indicates that this colloquium is fulfilling the goals of fostering collegiality and enhancing teaching at a research university. 


\section{References}

Bender, E., Dunn, M., Kendall, B., Larson, C., \& Wilkes. P. (Eds.). Quick hits: Successful Strategies by award winning teachers, Bloomington, IN: Indiana University Press.

Lamber, J., Ardizzone, T., Dworkin, T., Guskin, S., Olsen, D., Parnell, P., \& Thelen, D. (1993). A "community of scholars?": Conversations among mid career faculty at a public research university. To Improve the Academy, 12, 13-26.

Mangan, B. (Ed.). 147 practical tips for teaching professors. Madison, WI: Magna Publications.

Sorcinelli, M.D., \& Price, K.H. (1990). State-wide faculty development conference promotes vitality. To Improve the Academy, 9, 101-110.

Tobias, S. (1990). They're not dumb, they're different: Stalking the second tier. Tucson, AZ: Research Corporation.

Weimer, M. (1991). Improving college teaching. San Francisco: Jossey-Bass.

Whitcomb, S.W. (1986). When funds won't stretch: Faculty and organizational development projects for miniscule budgets. To Improve the Academy, 5, 84-92. 


\section{Appendix A}

5th Annual Colloquium on Teaching Excellence

May 22, 23, and 25, 1995

From Teaching Excellence to Learning Excellence

Monday, May 22

9:30-10:00 Registration/Refreshments, southeast entrance of classroom building

10:00-10:10 Welcome, Terry Roark, CR 202

10:10-10:15 Introduction of Keynote Speaker, Jim Wangberg

10:15-11:45 Keynote Address, "Through the lens of learning: how experiencing learning changes our teaching," Stephen Brookfield, CR 202.

11:45-12:00 Move to the Wyoming Union dining room for lunch.

12:00-1:15 Lunch/get acquainted.

1:15-1:30 Move to CR 202.

1:30-3:00 Workshop, "Becoming a critically reflective teacher," S. Brookfield, CR 202.

3:00-3:30 Break - SE entrance CR bldg.

3:30-4:45 Workshop continued

4:45-5:00 Move to the Foundation House for Reception.

5:00-6:30 Wine and Cheese Reception in the UW

Foundation House 
Tuesday, May 23

Perspectives on the Ecology and Cultures of Learning

8:30 The UW campus as a total learning environment, Jim Hurst (Moderator Wangberg), CR 202

9:00 Student panel - What makes a difference in my learning (Moderator Wangberg), CR 202

10:15 Break

10:45 Faculty panel - What makes a difference in my teaching and my students learning:

Moderator Jean Schaefer

Bruce Richardson, UW/CC

Mercedes Aguirre-Batty, Sheridan College

Maggi Murdock, UW/CC (for distance

education perspective)

Doug Bonett, Statistics-UW (for UW perspective on new technologies)

11:45 Move to Wyoming Union Dining Room for lunch.

12:00 Lunch

1:00 Move to afternoon sessions

1:15 The Best Learning Environments and Exemplary

Classrooms: Dreams and Designs (Moderator Wangberg)

1:45 Cohort Group Break out Sessions

(cohorts to be determined in advance based on colloquium participant list, and not strictly defined by discipline)

Cohort Facilitators:

Jim McClurg

Warrie Means

Jane Nelson

Andrea Reeve

Jean Schaefer

3:00 Break

3:30 Resume cohort sessions

5:00 End 
Thursday, May 25

8:00 Coffee and Orientation to Concurrent Sessions Motivating Students

Concurrent Sessions: choose to attend one of the following.

8:15 Session A: Creative approaches to instruction as a motivator, Michael Day (Moderator Landra Rezabek)

Session B: Humor and enthusiasm as a motivator, Ron Beiswenger (Moderator Ric Hoogestraat)

Session C: Grades as a motivator: "crossfire" Peter Huntoon and Robert Jenkins (Moderator Warrie Means)

9:00 Repeat Sessions A, B, C.

9:45 - 10:15 Break

10:15 Session D: Motivational issues in the diverse classroom, Judith Antell and Ni Coker (Moderator Jan Beeken)

Session E: Special activities as a motivator, Mary Burman (Moderator Andrea Reeve)

Session F: Internships as a motivator, Jo Chytka and Nancy Muecke (Moderator Amy Slack)

11:00 Repeat Sessions D, E, F.

11:45 Cohort meetings to finalize exemplary classroom proposals

12:30 Lunch

1:30 Cohort 1 presentation (10 $\mathrm{min}$.) and reactions (5 min.) (Moderator Wangberg)

1:45 Cohort 2 presentation/reaction

2:00 Cohort 3 presentation/reaction

2:15 Cohort 4 presentation/reaction

2:30 Cohort 5 presentation/reaction

2:45 Colloquium Wrap up and Evaluation (Moderator Wangberg) 


\section{Appendix B}

\section{EVALUATION}

4th Annual Colloquium on Teaching Excellence "Discovering Balanced Approaches to Teaching and Learning"

The Colloquium you are attending has been organized by the UW Center for Teaching Excellence and is supported in part by educational grants from the Chicago and NorthWestern Transportation Company and U S WEST. Your opinions about the effectiveness and usefulness of the Colloquium and ideas for improvement will help us in planning next year's Colloquium. You are encouraged to fill in your evaluation at the completion of each session. You will have time to finish your evaluation before you leave on Thursday. Thank you.

The first section of the questionnaire asks questions about the effectiveness and usefulness of the various presentations. Please indicate your opinion using the following scale:

\section{EFFECTIVENESS:}

1. Very effective

2. Effective, but could have been better

3. Average

4. Not effective

5. I did not attend this presentation

\section{USEFULNESS:}

1. Very useful, I intend to apply the ideas and materials from this presentation as soon as possible.

2. Useful, however, I won't be able to use all of the material in my classes.

3. This material was useful, but not applicable to courses I teach.

4. Not useful.

5. I did not attend this presentation. 
Effectiveness: 1. Very effective 2. Effective 3. Average 4. Not effective 5. Did not attend

Usefulness 1. Very useful 2. Useful 3. Useful, not applicable 4. Not useful 5. Did not attend

\section{Plenary Presentations}

1. Keynote Address, Len Barron, "Walking Lightly ... A Portrait of Einstein."

$\begin{array}{llllll}\text { Effectiveness } & 1 & 2 & 3 & 4 & 5 \\ \text { Usefulness } & 1 & 2 & 3 & 4 & 5\end{array}$

2. Workshop, Len Barron, "Thoughtfulness and Fun"

$\begin{array}{llllll}\text { Effectiveness } & 1 & 2 & 3 & 4 & 5 \\ \text { Usefulness } & 1 & 2 & 3 & 4 & 5\end{array}$

3. Workshop, Thom Edgar and Ray Jacquot, "Myers-Briggs Type Inventory: Understanding Interactions Between Faculty and Students"

$\begin{array}{llllll}\text { Effectiveness } & 1 & 2 & 3 & 4 & 5 \\ \text { Usefulness } & 1 & 2 & 3 & 4 & 5\end{array}$

4. Provost Karnig, "Historical Trends"

$\begin{array}{llllll}\text { Effectiveness } & 1 & 2 & 3 & 4 & 5 \\ \text { Usefulness } & 1 & 2 & 3 & 4 & 5\end{array}$

5. University of Wyoming Teaching Award Winners Panel "Balancing Teaching, Research, and Service: Keeping All the Balls in the Air"

$\begin{array}{llllll}\text { Effectiveness } & 1 & 2 & 3 & 4 & 5 \\ \text { Usefulness } & 1 & 2 & 3 & 4 & 5\end{array}$

Comments: 


\section{Concurrent Presentations/workshops}

6. Mary Ann Harlow, Karen Lange, Sally Scott, Paula Wolfe, "Teaching Tools Available on the Internet"

$\begin{array}{llllll}\text { Effectiveness } & 1 & 2 & 3 & 4 & 5 \\ \text { Usefulness } & 1 & 2 & 3 & 4 & 5\end{array}$

7. Charlotte Farr, Barbara Hakes, Landra Rezabek, Karen Weibel, "Lessons Learned from Distance Teaching: On Campus Implications"

$\begin{array}{llllll}\text { Effectiveness } & 1 & 2 & 3 & 4 & 5 \\ \text { Usefulness } & 1 & 2 & 3 & 4 & 5\end{array}$

8. Ritchie Boyd, "Computing Tools for Instruction"

$\begin{array}{llllll}\text { Effectiveness } & 1 & 2 & 3 & 4 & 5 \\ \text { Usefulness } & 1 & 2 & 3 & 4 & 5\end{array}$

9. Andy Bryson, "Media Tools for Instruction"

$\begin{array}{llllll}\text { Effectiveness } & 1 & 2 & 3 & 4 & 5 \\ \text { Usefulness } & 1 & 2 & 3 & 4 & 5\end{array}$

10. Mary Ann Harlow, Karen Lange, Sally Scott, Paula Wolfe, "Teaching Tools Available on the Internet - Hands-On Session"

$\begin{array}{llllll}\text { Effectiveness } & 1 & 2 & 3 & 4 & 5 \\ \text { Usefulness } & 1 & 2 & 3 & 4 & 5\end{array}$

11. Charlotte Farr, Barbara Hakes, Landra Rezabek, Karen Weibel, "Lessons Learned from Distance Teaching: On Campus Implications Hands-On Session"

$\begin{array}{llllll}\text { Effectiveness } & 1 & 2 & 3 & 4 & 5 \\ \text { Usefulness } & 1 & 2 & 3 & 4 & 5\end{array}$

12. Ritchie Boyd, "Computing Tools for Instruction Hands-On Session"

$\begin{array}{llllll}\text { Effectiveness } & 1 & 2 & 3 & 4 & 5 \\ \text { Usefulness } & 1 & 2 & 3 & 4 & 5\end{array}$


13. Andy Bryson, "Media Tools for Instruction Hands-On Session"

$\begin{array}{llllll}\text { Effectiveness } & 1 & 2 & 3 & 4 & 5 \\ \text { Usefulness } & 1 & 2 & 3 & 4 & 5\end{array}$

14. Len Barron, "On The Pleasure of Growing Older"

$\begin{array}{llllll}\text { Effectiveness } & 1 & 2 & 3 & 4 & 5 \\ \text { Usefulness } & 1 & 2 & 3 & 4 & 5\end{array}$

15. CTE Resource Room

$\begin{array}{llllll}\text { Effectiveness } & 1 & 2 & 3 & 4 & 5 \\ \text { Usefulness } & 1 & 2 & 3 & 4 & 5\end{array}$

16. Michael Enos, Andrea Reeve, Sue Yarbrough, "Involving Students in Teaching Experiences"

$\begin{array}{llllll}\text { Effectiveness } & 1 & 2 & 3 & 4 & 5 \\ \text { Usefulness } & 1 & 2 & 3 & 4 & 5\end{array}$

17. Ron Canterna, "Cooperative and Collaborative Learning"

$\begin{array}{llllll}\text { Effectiveness } & 1 & 2 & 3 & 4 & 5 \\ \text { Usefulness } & 1 & 2 & 3 & 4 & 5\end{array}$

18. Robert Kitchin, Charles Ksir, Michael Parker, "Managing Large Classes"

$\begin{array}{llllll}\text { Effectiveness } & 1 & 2 & 3 & 4 & 5 \\ \text { Usefulness } & 1 & 2 & 3 & 4 & 5\end{array}$

19. Don Warder, "Graduate Assistant Teacher Training"

$\begin{array}{llllll}\text { Effectiveness } & 1 & 2 & 3 & 4 & 5 \\ \text { Usefulness } & 1 & 2 & 3 & 4 & 5\end{array}$

20. Laura Bennett, Dolores Cardona, Chris Primus, "Working with Diverse Student Populations"

$\begin{array}{llllll}\text { Effectiveness } & 1 & 2 & 3 & 4 & 5 \\ \text { Usefulness } & 1 & 2 & 3 & 4 & 5\end{array}$

21. Rod Lang, "The Legal Issues Related to Teaching" $\begin{array}{llllll}\text { Effectiveness } & 1 & 2 & 3 & 4 & 5\end{array}$ 
$\begin{array}{llllll}\text { Usefulness } & 1 & 2 & 3 & 4 & 5\end{array}$

22. Donna Whitson, "Assessing Learning"

$\begin{array}{llllll}\text { Effectiveness } & 1 & 2 & 3 & 4 & 5 \\ \text { Usefulness } & 1 & 2 & 3 & 4 & 5\end{array}$

23. Leonard Asimow, "Teaching Quantitative Reasoning Across the Curriculum"

$\begin{array}{llllll}\text { Effectiveness } & 1 & 2 & 3 & 4 & 5 \\ \text { Usefulness } & 1 & 2 & 3 & 4 & 5\end{array}$

Comments:

\section{The Colloquium in General:}

Appropriateness of time of year:

a. The present time was appropriate.

b. One of the following would be more appropriate:

Just before the beginning of fall semester The week immediately following commencement At the end of summer session During Christmas break During spring break Other:

Colloquium length:

a. The length was about right

b. Too much information to assimilate in three days; Colloquium should be longer. 
c. The Colloquium should be 5 days with one or two half-day recesses.

d. The Colloquium should be 4 days.

e. The Colloquium should be conducted during mornings for 5 days.

f. Other:

The Colloquium would be more effective if it were conducted at an off-campus site for 3 consecutive days and participants housed for two evenings:

Strongly Agree Agree Neutral Disagree Strongly Disagree
1
2
3
4
5

The mix of outside speakers and University of Wyoming presenters was:

a. Satisfactory.

b. I would have enjoyed hearing from more outside presenters.

c. I would have enjoyed hearing from more UW colleagues.

The amount of time allowed for interaction with fellow participants was:

a. Satisfactory

b. Insufficient

c. Too great

d. Lunch time provided ample time for interaction with colleagues.

The material presented during the Colloquium was in general:

a. Old material with which I am quite familiar.

b. A review of old material, but hadn't thought about for some time.

c. New material that I found interesting and useful.

d. New material that I probably won't often use.

e. Other: 
Would you recommend a similar Colloquium to your academic colleagues?

a. Highly recommend

b. Recommend

c. Maybe, not sure

d. Would not recommend

e. No opinion

Please give us suggestions for topics for future Colloquia.

Additional comments you have about the Colloquium: 